\title{
Eco-tourists as Pro-environmental Tourists: A Case of the Hunza Valley, Mountainous Area of Pakistan
}

\author{
Rehmat Karim, Faqeer Muhammad, Nizam ud Din, Mehtab Alam \\ Karakoram International University, Gilgit-Baltistan, Pakistan
}

\begin{abstract}
Environmental impact of tourism is a critical issue in the mountain regions around the world. This research aims to study the eco-tourists and their attitude towards environment during their visit to the Hunza Valley. The data were collected by a set of questionnaires distributed among 300 foreign tourists who visited Hunza for the tourism activities, and 10 questionnaires were distributed to tour leaders to get their opinions about which type of tourist is pro-environment tourist. Questionnaires were processed though Statistical Package for Social Sciences (SPSS) software. Geographic Information System (GIS) software (ArcMap 9.2) was also used for mapping of the study area. The research outcomes revealed that eco-tourists strongly agreed that their behavior is positive towards environmental preservation, following the codes of conduct, local laws and customs, and caring about health issues. The majority of tour leaders also ranked eco-tourists as pro-environment tourists. On the basis of the results, the authors recommend to attract more eco-tourists in the Hunza Valley because of their friendly nature towards the environment.
\end{abstract}

Keywords: eco-tourist, environment, pro-environment tourist, Hunza, Pakistan

\section{Introduction}

Environmental issues, especially climate change and unexpected weather conditions, are shocking not only for the residents of any specific upstream area; rather, it affects other downstream areas. Like the 2010 and 2011 floods in Pakistan have not only destroyed the country's infrastructure but badly affected the economic conditions as well. Tourism has been a cause of environmental degradation at many destinations. Therefore, it is very important to know which type of tourist is more pro-environmental, so that it can be suggested to tourism planners to attract more environment-friendly tourists (EFTs).

The main objective of this paper is to look at the relationship between eco-tourists and environment and how different types of tourists behave towards the environment during their visit.

The debate of environmental realism vis-à-vis the postmodern view that the environment is purely a social construction (Dickens, 1996; Holden, 2003) is the one that is pertinent to how nature is perceived and subsequently managed. The activity of tourism is dependent upon the perception of the environment of a

Rehmat Karim, lecturer, Ph.D. scholar, Integrated Mountain Area Research Centre (IMARC), Karakoram International University.

Faqeer Muhammad, chairman, Department of Economics, Karakoram International University.

Nizam ud Din, lecturer, Department of Business Management, Karakoram International University.

Mehtab Alam, lecturer, Department of Business Management, Karakoram International University.

Correspondence concerning this article should be addressed to Rehmat Karim, Integrated Mountain Area Research Centre (IMARC), Karakoram International University, Gilgit-Baltistan, Pakistan. Email: rehmat@kiu.edu.pk. Tel.: +92-346-9239050. 
destination as being desirable. Yet to date, little has been understood about the attitude held by the tourists towards the nature and the environment of destinations they visit. Ecotourism is considered to be small scale with limited ecological and social impacts when compared with traditional tourism. Ecotourism limits the number of guests who visit a destination, as there is adherence to the physical carrying capacity of the tourist resource base (Simon, Memory, Karigambe, \& Mudzengi, 2011). Ecotourism is a form of tourism which minimizes negative impacts, contributes to conservation, directs economic benefits to local people, and further provides opportunities for local people to enjoy natural areas (Fennel, 2001; Simon et al., 2011). Malim and Birch (1989) and Holden (2003) suggested that attitude has three components: the "cognitive”, the "affective", and the "behavioral". The "cognitive" component relates to our perception, for example, a cognitive expression could be that "mountain areas are beautiful". The "affective" response builds upon the cognitive expression developing feelings associated with the object. An effective response may be that "mountain areas are beautiful and provide me with happiness from looking at them". The "behavioral" response relates to intentions towards the object based upon the "cognitive" and "affective" responses, for instance, "I intend to go walking in the mountains". Subsequently, a mix of cultural influence and individual psychology manifests itself in behavior (Holden, 2003). One mechanism for farming tourist experience has been developed in the field of environment psychology. Different but overlapping modes of interactions with the environment were identified (Ittleson, Franck, \& O’Hanlon, 1976; Holden, 2003).

Historical, biological, and cultural conservation, preservation, sustainable development etc. are some of the fields closely related to ecotourism (Iqball, Salequzzaman, Haque, Islam, \& Ahmed, 2010). Ecotourism encompasses a broad spectrum of societal concerns related to complex social, ecological, and economic relationships. It is about framing a "win-win" situation for all the involved interests and striking a balance between environmental sustainability and community's economic development (Moinuddin \& Begum, 2004). Ecotourism is necessary to mitigate the impact of conservation policies (Gurung \& Seeland, 2008). Without this reorientation, efforts to achieve sustainable development in remote rural areas will be difficult to achieve (Gurung \& Seeland, 2008). Most definitions of ecotourism include notions of positive environmental ethics (Lemelin, Fennell, \& Smale, 2008) and consideration for the environmental preservation. The ecotourism has multiple advantages, such as environment conservation, wildlife preservation, promoting cultural objectives, and historical points of interest (Bauer, 2011). Ecotourism can be approached as reconciliation of two antagonistic dimensions, namely, tourism and environment (Hovardas \& Poirazidis, 2006). Ecotourism is often considered to be a potential strategy to support conservation of natural ecosystems while, at the same time, promoting sustainable local development (Ross \& Wall, 1999). Eco-tourists are a subset of EFTs, as eco-tourists are generally defined by their interest in nature-based activities (Dolnicar, Crouch, \& Long, 2008). Because of the strong orientation in ecotourism research to understand the nature of eco-tourists and because eco-tourists are a subset of EFTs, the ecotourism literature presently provides the main source of knowledge within tourism research about EFTs (Dolnicar et al., 2008). Ecotourism is defined as "responsible travel to natural areas that conserves the environment and sustains the well-being of local people” (Dolnicar et al., 2008, p. 207).

\section{Study Area (Hunza)}

Hunza is situated in the northern part of Pakistan bordering with China (see Figure 1). The opening up of the Karakoram Highway in 1978 ended this isolation and saw a rapid pouring in of tourists. With an altitude of over 2,400 m, Hunza receives an annual rainfall of $145 \mathrm{~mm}$. The wettest months are from April to August, and 
the area's dry period starts from October to March of the next year. The Hunza Valley is divided into three regions, the lower (Shina) region, the central (brushal) region, and the upper (Gojal) region (Al-Jalaly, Nazeer, \& Qutub, 1995). Gilgit-Baltistan with their high altitude mountains of the Himalayas, Hindukush, and Karakoram Ranges attract a particular group of tourists, mountain trekkers, and mountain climbers. It is the confluence of the world's three mighty mountain ranges - the Himalayas, the Karakoram, and the Hindukush. Some of the world's highest peaks are found here (Ministry of Tourism [MOT], 2006). These attract a large number of mountaineers from all over the world. In between these peaks, there are heavenly valleys, the largest glaciers outside the polar areas, bubbling springs, blue lakes, and rivers. The area is ideal for mountaineering, trekking, and just nature walking. Hunza can also attract many eco-friendly tourists to see its clean and preserved environment (see Figures 2 and 3).

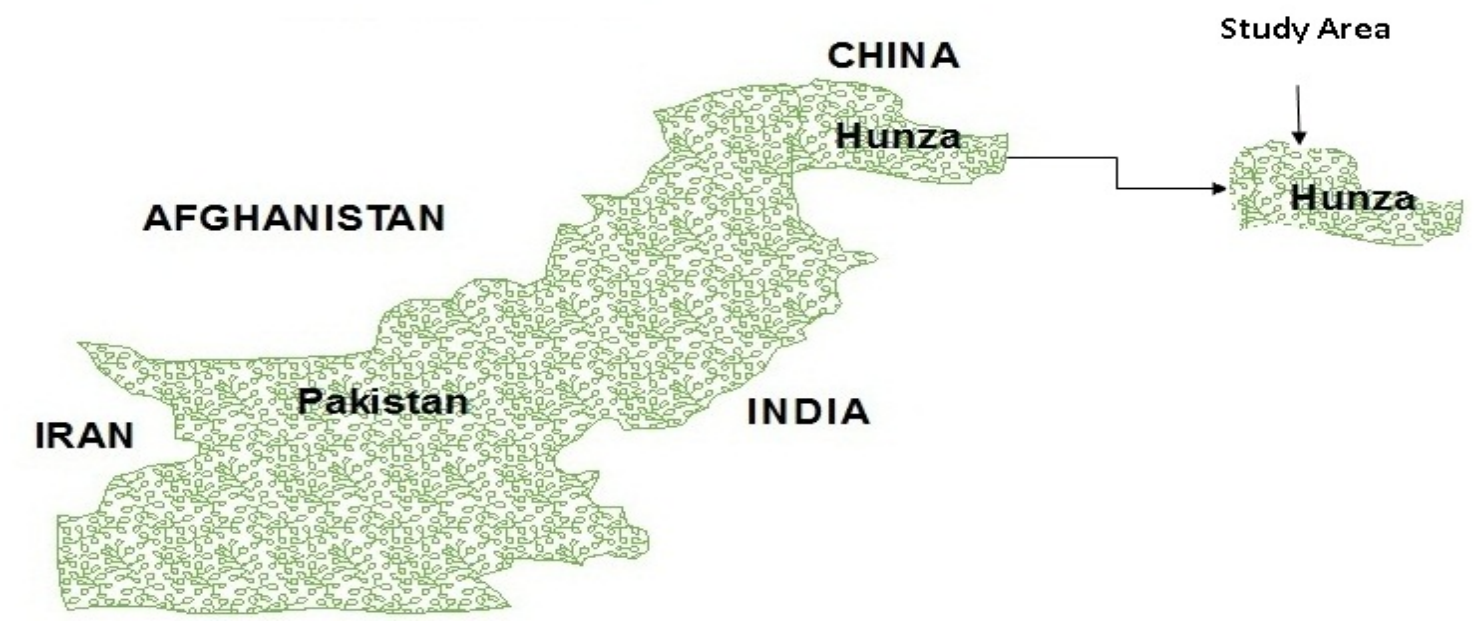

Figure 1. Map of study area.

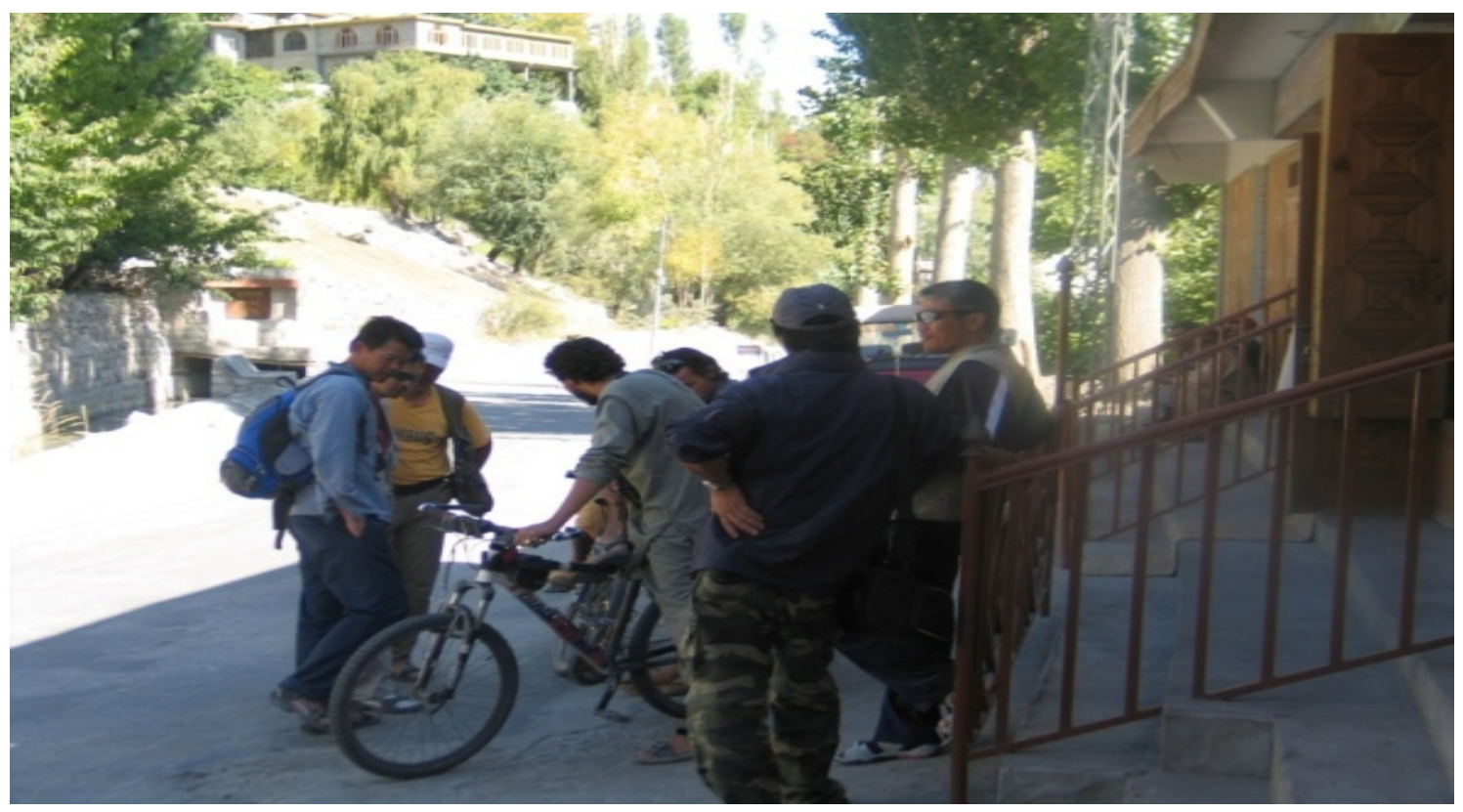

Figure 2. Snapshots of the Hunza Valley (by the authors). 


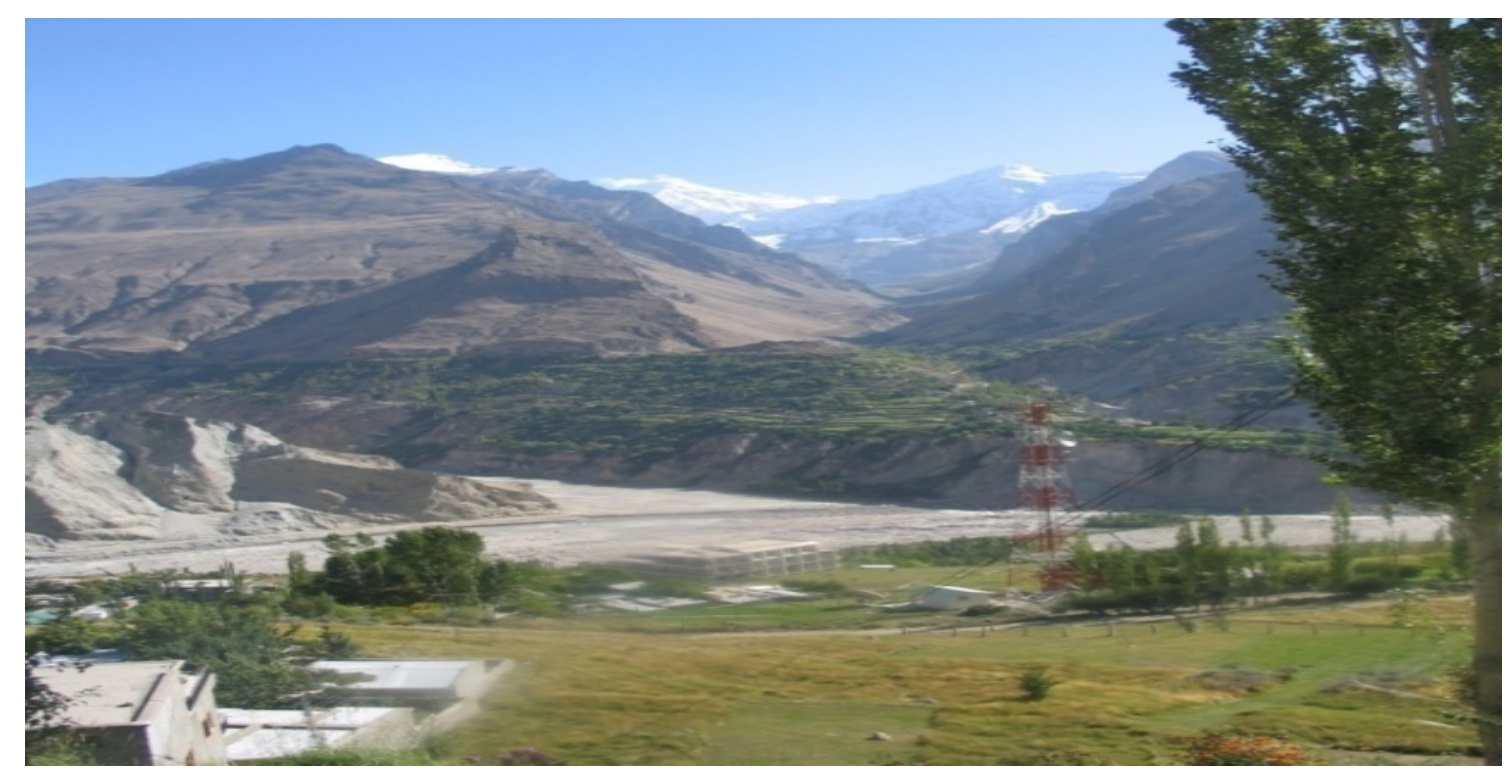

Figure 3. Snapshots of the Hunza Valley (by the authors).

\section{Material and Methods}

In this study, the authors used the explorative research method to investigate the behavior of tourists towards environment in the Hunza Valley. Two types of respondents were identified to get their opinions: tourists and tour leaders. In order to conduct the research, 300 questionnaires were distributed among tourists who participated in tourism activities. Questionnaires were distributed at camps, lodges, hotels, and trekking routes. Data collection processes took 35 days, and on average, nine questionnaires were distributed per day with one respondent taking on average 15-20 minutes to fill the questionnaire. Ten structured questionnaires were distributed to tour leaders, and two semi-structured interviews were also conducted with tour leaders at Hotel Embassy, Karim Abad, Hunza. Before distributing the questionnaires, the authors asked for respondents' consent to fill the questionnaires and briefed them about the study.

The questionnaire mainly comprises three parts. Part 1 is about demographic characteristics of respondents, Part 2 is about travel characteristics, and Part 3 is mainly about tourists' behavior in Hunza. The questionnaire is expressed by the Likert scale: 5-strongly agree, 4-agree, 3-neither agree nor disagree, 2-disagree, and 1 -strongly disagree. Two open-ended questions were also included in the questionnaire.

\section{Results and Discussion}

Among 300 respondents of this research, 34.3\% of the respondents visiting Hunza were Asians, 59.2\% were male, and $52 \%$ were between the ages of 25 and 34, whereas $42 \%$ had bachelor degrees and $47.7 \%$ of respondents were related to different professions (see Table 1).

Table 1

Statistics of Majority Tourists in Terms of Demographic Characteristics

\begin{tabular}{lllll}
\hline Nationality & Age & Gender & Education & Occupation \\
\hline Asian & $25-34$ & Male & Bachelors & Professional \\
\hline 34.3 & 52 & 59.2 & 42 & 47.7 \\
\hline
\end{tabular}

Note. All figures are given in percentage. 
The travel characteristics of the sample indicated that $49.3 \%$ of respondents who visited Hunza were for pleasure purposes, $52.3 \%$ stayed in "lodges/guest houses", $45.7 \%$ of tourists stayed for "more than a week", 43.7\% tourists had mountain tourism experience between "1-2 years", 39.3\% were "mountaineers", 39.7\% of them traveled in the group of " $1-2$ persons", and $39.7 \%$ of tourists "did not hire any guide or porter", whereas $41.7 \%$ of tourists visited Hunza for "viewing natural scenes" and $47.7 \%$ tourists came for "recreational tourism" (see Table 2).

Table 2

Statistics of Majority Tourists in Terms of Travel Characteristics

\begin{tabular}{|c|c|c|c|c|c|c|c|c|}
\hline $\begin{array}{l}\text { Purpose of } \\
\text { visit }\end{array}$ & $\begin{array}{l}\text { Length of } \\
\text { stay }\end{array}$ & Type of tourist & $\begin{array}{l}\text { Travel party } \\
\text { size }\end{array}$ & Activity & $\begin{array}{l}\text { Tourism } \\
\text { type }\end{array}$ & $\begin{array}{l}\text { Type of } \\
\text { accommodation } \\
\text { used }\end{array}$ & $\begin{array}{l}\text { Experience of } \\
\text { mountain } \\
\text { tourism }\end{array}$ & $\begin{array}{l}\text { Status of local } \\
\text { employed }\end{array}$ \\
\hline Pleasure & $\begin{array}{l}\text { More than } \\
\text { a week }\end{array}$ & Mountaineers & 1-2 persons & $\begin{array}{l}\text { Viewing } \\
\text { natural } \\
\text { scenes }\end{array}$ & Recreational & $\begin{array}{l}\text { Lodges/guest } \\
\text { house }\end{array}$ & $1-2$ years & No guide/porter \\
\hline 49.3 & 45.7 & 39.3 & 39.7 & 41.7 & 47.3 & 52.3 & 43.7 & 39.7 \\
\hline
\end{tabular}

Note. All figures are given in percentage.

The behavior of tourists in terms of "I followed the codes of conduct for environmental preservation" got the highest mean score (4.33), followed by their behavior of "The environment of Hunza provides a good place for enjoying wilderness" (4.32), "I felt a sense of being close to nature while on a tour in Hunza" (4.32), "I adhered to these codes" (4.26), "I did respect the information given to me about the mountain ecosystem and biodiversity conservation (threatened species, share local resources)" (4.23), "I followed the information about local laws, customs, and appropriate behavior (protocols for photography, private local sites, custom laws, and souvenir restrictions)" (4.11), "I did care of health and safety issues that may be relevant to me in this tours (danger areas, minimum health and fitness requirement, equipment and vehicle standards, and batteries for lighting and equipment)" (3.88), "Tourism activities should not be allowed if they have negative impacts upon the natural environment” (3.83), "If I thought tourism activities could harm the environment, would stop getting involved in tourism activities” (3.76), and “Tourism activities have spoilt Hunza's environment” (2.98) (see Table 3).

Table 3

Mean Scores of Statements of "Behavior of Tourists" in Hunza

\begin{tabular}{lcc}
\hline Statement of "behavior of tourists" & Mean & SD \\
\hline I followed the codes of conduct for environmental preservation. & 4.33 & 0.764 \\
I felt a sense of being close to nature while on a tour in Hunza. & 4.32 & 0.812 \\
The environment of Hunza provides a good place for enjoying wilderness. & 4.32 & 0.844 \\
I adhered to these codes. & 4.26 & 0.810 \\
I did respect the information given to me about the mountain ecosystem and biodiversity conservation & 4.23 & 0.883 \\
(threatened species, share local resources). & 4.11 & 0.775 \\
I followed the information about local laws, customs, and appropriate behavior (protocols for photography, & & \\
private local sites, customs laws, and souvenir restrictions). & 1.089 \\
I did care of health and safety issues that may be relevant to me in this tour (danger areas, minimum health and 3.88 & 3.83 & 1.006 \\
fitness requirement, equipment and vehicle standards, and batteries for lighting and equipment). & 3.76 & 0.931 \\
Tourism activities should not be allowed if they have negative impacts upon the natural environment. & 2.98 & 1.000 \\
If I thought tourism activities could harm the environment, I would stop getting involved in tourism activities. & 3 \\
Tourism activities have spoilt Hunza's environment. & 2
\end{tabular}

Note. Likert scale: 5-strongly agree, 4-agree, 3-neither agree nor disagree, 2-disagree, and 1-strongly disagree. 
Tables 4, 5, 6, and 7 show the tour leaders' opinions about different types of tourists visiting Hunza and their behavior towards environment during their visit to Hunza. The majority of tour leaders have ranked eco-tourists as pro-environment tourists. For the statement "which type of tourist follows more the codes of conduct for environmental preservation?”, 90\% of tour leaders have considered that eco-tourists are pro-environmental tourists (see Table 4).

Table 4

Opinions of Tour Leaders About Tourists'Behavior Towards Environment $(N=10)$

\begin{tabular}{llc}
\hline & Which type of tourist follows more the codes of conduct for environmental preservation? \\
\hline Type of tourist & Frequency & Percentage \\
\hline Mountaineer & $N=1$ & 10 \\
Trekker & $N=0$ & 0 \\
General tourists & $N=0$ & 0 \\
Eco-tourists & $N=9$ & 90 \\
\hline
\end{tabular}

For the statement "which type of tourist did more respect the information given about the mountain ecosystem and biodiversity conservation (threatened species, share local resources)?”, 80\% of tour leaders have ranked eco-tourists as pro-environmental tourists (see Table 5).

Table 5

Opinions of Tour Leaders About Tourists' Behavior Towards Environment $(N=10)$

\begin{tabular}{llc}
\multicolumn{2}{c}{ Which type of tourist did more respect the information given about the mountain ecosystem and biodiversity conservation } \\
(threatened species, share local resources)?
\end{tabular}

For the statement "which type of tourist follows more the information about local laws, customs, and appropriate behavior (protocols for photography, private local sites, customs laws, and souvenir restrictions)?”, $70 \%$ of tour leaders have opined that eco-tourists are pro-environmental tourists (see Table 6).

Table 6

Opinions of Tour Leaders About Tourists' Behavior Towards Environment $(N=10)$

\begin{tabular}{llc}
\multicolumn{2}{c}{$\begin{array}{c}\text { Which type of tourist follows more the information about local laws, customs, and appropriate behavior (protocols for } \\
\text { photography, private local sites, customs laws, and souvenir restrictions)? }\end{array}$} \\
\hline Type of tourist & Frequency & Percentage \\
\hline Mountaineer & $N=2$ & 20 \\
Trekker & $N=1$ & 10 \\
General tourists & $N=0$ & 0 \\
Eco-tourists & $N=7$ & 70 \\
\hline
\end{tabular}

For the statement "which type of tourist did care of health and safety issues that may be relevant in this tour (danger areas, minimum health and fitness requirement, equipment and vehicle standards, and batteries for lighting and equipment)?”, 60\% of tour leaders have ranked eco-tourists as pro-environmental tourists (see Table 7). 
Table 7

Opinions of Tour Leaders About Tourists'Behavior Towards Environment $(N=10)$

\begin{tabular}{lcc}
\multicolumn{2}{c}{$\begin{array}{c}\text { Which type of tourist did care of health and safety issues that may be relevant in this tour (danger areas, minimum health and } \\
\text { fitness requirement, equipment and vehicle standards, batteries for lighting and equipment)? }\end{array}$} \\
\hline Type of tourist & Frequency & Percentage \\
\hline Mountaineer & $N=0$ & 0 \\
Trekker & $N=2$ & 20 \\
General tourists & $N=2$ & 20 \\
Eco-tourists & $N=6$ & 60 \\
\hline
\end{tabular}

This paper is also an attempt to differentiate the eco-tourists from trekkers, mountaineers, and general tourists. Although the arrival of eco-tourists was in smaller number than other three types, i.e., general tourists, trekkers, and mountaineers, they were more sensitive and concerned with environmental pollution, and their behavior was positive in terms of following the codes of conduct, caring the health and other related issues, following the local laws, customs, and feeling closer to nature when they visit Hunza. The majority of the tour leaders have also considered that eco-tourists are more environment-friendly. So eco-tourism should be promoted, as eco-tourists are more responsible and environment-friendly. Research results indicated that eco-tourists behaved positively towards following codes of conduct about environmental preservation during their visit to Hunza.

\section{Conclusion}

The results are not the authors' own judgments about the tourism practices and its effects on environment; rather, researchers have analyzed the opinions of the tourists and tour leaders who are neutral to judge the behaviors of tourists. Eco-tourism or environment-friendly activities must be initiated in Hunza, which would help reduce the negative effects of tourism and allow both tourists and local people to benefit from more sustainable tourism.

\section{References}

Al-Jalaly, S. Z., Nazeer, M. M., \& Qutub, S. A. (1995). Tourism for local community development in the mountain areas of NWFP and the northern areas of Pakistan: Phase two-case studies of Kalam and Hunza. ICIMOD Discussion Paper, Series No. MEI 95/12, Kathmandu, Nepal, pp. 56-97.

Bauer, V. (2011). Agro-tourism: A piece of history at our fingertips. Cactus Tourism Journal, 2(1), 37-40.

Dickens, P. (1996). Reconstructing nature: Alienation, emancipation, and the division of labour. London: Routledge.

Dolnicar, S., Crouch, G. I., \& Long, P. (2008). Environment-friendly tourists: What do we really know about them? Journal of Sustainable Tourism, 16(2), 197-210.

Fennel, D. A. (2001). A content analysis of ecotourism definitions. Current Issues in Tourism, 4(5), 403-421.

Gurung, D. B., \& Seeland, K. (2008). Ecotourism in Bhutan: Extending its benefits to rural communities. Annals of Tourism Research, 35(2), 489-508.

Holden, A. (2003). Investigating trekkers' attitude to the environment of Annapura, Nepal. Tourism Management, 24(3), 341-344. Hovardas, T., \& Poirazidis, K. (2006). Evaluation of the environmentalist dimension of eco-tourism at the Dadia forest reserves (Greece). Environmental Management, 38(5), 810-822.

Iqball, M. S., Salequzzaman, M., Haque, S. E., Islam, M. R., \& Ahmed, S. (2010). Ecotourism in the Sundarbans and its surrounding-A possible sustainable option for alternative livelihood development. Bangladesh Research Publications Journal, 4(3), 244-253.

Ittleson, W. H., Franck, K. A., \& O’Hanlon, T. J. (1976). The nature of environmental experience. In S. Wagner, B. S. Cohen, \& B. Kaplan (Eds.), Experiencing the environment (pp. 187-206). New York, N.Y.: Plenum Press. 
Lemelin, R. H., Fennell, D., \& Smale, B. (2008). Polar bear viewers as deep ecotourists: How specialised are they? Journal of Sustainable Tourism, 16(1), 42-62.

Malim, T., \& Birch, A. (1989). Social psychology. Basingstoke: The Macmillan Press, Ltd..

Ministry of Tourism [MOT]. (2006). Tourism in Pakistan. Retrieved from http://www.pakistan tourism.gov.pk/pdf/Tourism\%20in\%20pakistan\%202006.pdf

Moinuddin, G., \& Begum, H. (2004). An investigation into the conceptual framework and policy requirements for its growth in Bangladesh. Jahangirnagar Planning Review, 2, 67-82.

Ross, S., \& Wall, G. (1999). Ecotourism: Towards congruence between theory and practice. Tourism Management, 20(1), 123-132.

Simon, C., Memory, M., Karigambe, P., \& Mudzengi, B. K. (2011). The theory and practice of ecotourism in Southern Africa. Journal of Hospitality Management and Tourism, 2(2), 14-21. 